University of Nebraska - Lincoln

DigitalCommons@University of Nebraska - Lincoln

Entomology Papers from Other Sources

Entomology Collections, Miscellaneous

2005

\title{
Sperm stratification and paternity success in red flour beetles
}

Sara M. Lewis

Tufts University

Annika Kobel

Tufts University

Tatyana Fedina

Tufts University

Richard W. Beeman

USDA-ARS

Follow this and additional works at: https://digitalcommons.unl.edu/entomologyother

Part of the Entomology Commons

Lewis, Sara M.; Kobel, Annika; Fedina, Tatyana; and Beeman, Richard W., "Sperm stratification and paternity success in red flour beetles" (2005). Entomology Papers from Other Sources. 5.

https://digitalcommons.unl.edu/entomologyother/5

This Article is brought to you for free and open access by the Entomology Collections, Miscellaneous at DigitalCommons@University of Nebraska - Lincoln. It has been accepted for inclusion in Entomology Papers from Other Sources by an authorized administrator of DigitalCommons@University of Nebraska - Lincoln. 


\title{
Sperm stratification and paternity success in red flour beetles
}

\author{
SARA M. LEWIS ${ }^{1}$, A N NIKA KOBEL ${ }^{1}$, TA T Y A A FEDINA ${ }^{1}$ and \\ R I C H A R W. B E E M A N 2 \\ ${ }^{1}$ Department of Biology, Tufts University, Medford, Massachusetts, U.S.A. and ${ }^{2}$ USDA, ARS, Grain Marketing and \\ Production Research Center, Manhattan, Kansas, U.S.A.
}

\begin{abstract}
When females are inseminated by multiple males, male paternity success (sperm precedence) is determined by the underlying processes of sperm storage and sperm utilization. Although informative for many questions, two-male sperm competition experiments may offer limited insight into natural mating scenarios when females are likely to mate with several males. In this study, genetic markers in Tribolium castaneum are used to trace paternity for multiple sires, and to determine whether displacement of stored sperm that occurs after a third mating equally affects both previous mates, or if fertilizations are disproportionately lost by the female's most recent mate. For 20 days after triple-matings, first males retain significantly higher paternity success (relative to first male paternity in double-matings) compared with second males. These results demonstrate that when females remate before sperm mixing occurs, sperm stratification results in differential loss of sperm from the most recent mate. This study provides insight into the mechanisms underlying sperm precedence in a promiscuous mating system, and suggests that $T$. castaneum females could limit paternity success of particular mates by remating with more highly preferred males.
\end{abstract}

Key words. Multiple mating, polyandry, sexual selection, sperm competition, sperm precedence, Tribolium.

\section{Introduction}

Whenever females are multiply inseminated by different males, sperm precedence (nonrandom differential fertilization success among mating males) will represent an important component of male reproductive success (Parker, 1970; Simmons, 2001). Sperm precedence is most often empirically measured using sperm competition experiments with two males, and estimated as $P_{2}$, the proportion of progeny sired by the second male. Although this double-mating protocol has provided valuable insights into both interspecific and intraspecific variation in sperm precedence (reviewed by Lewis \&

Correspondence: S. M. Lewis, Department of Biology, Tufts University, Medford, Massachusetts 02155, U.S.A. Tel.: +1 617 6273548; fax: +1 617 6273805; e-mail: sara.lewis@tufts.edu
Austad, 1990; Simmons \& Siva-Jothy, 1998; Simmons, 2001), two areas deserve greater attention. First, little is known about sperm precedence patterns under more realistic scenarios when females mate at varying intervals with several males, with such knowledge limited partially by the difficulty of determining paternity for multiple sires. In addition, for most species, the physiological mechanisms responsible for sperm precedence patterns are poorly understood due to limited knowledge of the underlying processes of sperm storage and utilization (Eberhard, 1996; Simmons, 2001).

In the present study, sperm precedence patterns after double- and triple-matings are investigated in the red flour beetle Tribolium castaneum Herbst (Coleoptera: Tenebrionidae). This species is an economically important stored product pest in which both sexes mate repeatedly over adult lifespans of a year or more (Sokoloff, 1974; Lewis \& Iannini, 1995; Lewis, 2004). 
This organism affords many advantages for studies of sperm precedence, including the availability of numerous genetic markers for paternity determination (Sokoloff, 1974). Previous studies have demonstrated that third males in triple-mating sequences achieve levels of lastmale sperm precedence comparable with that of second males in double-mating sequences (Lewis \& Jutkiewicz, 1998; Arnaud etal., 2001). In addition, previous studies in this species have provided detailed knowledge concerning spermatophore transfer and sperm storage dynamics within females after single matings (Bloch Qazi etal., 1996, 1998). Tribolium castaneum females store sperm in a spermatheca consisting of two to four nonextensible, narrow tubules connected to the anterior bursa copulatrix through a common duct (Sinha, 1953; Fedina \& Lewis, 2004). Lewis \& Jutkiewicz (1998) found that the female spermatheca is filled to capacity (approximately 7500 sperm) after two copulations. Thus, at the third and each subsequent copulation, any additional sperm storage necessarily entails loss of sperm stored from previous males.

In promiscuous mating systems, an important unresolved question concerns whether reduced fertilization success is distributed evenly among previous males when a female remates. Models of sperm competition processes (Parker et al., 1990) allow predictions of male fertilization success based on patterns of sperm storage and utilization. Under a model of sperm stratification, a female's subsequent matings are predicted to differentially reduce last male fertilization success to a greater extent than the fertilization success of any previous mates. In the present study, $T$. castaneum males with genetic markers are used to examine temporal patterns of sperm precedence after double- and triple-matings, and to determine whether such sperm displacement equally affects all previous mates, or if a female's most recent mate disproportionately loses fertilizations.

\section{Materials and methods}

\section{Model of sperm precedence mechanisms}

To test the hypothesis that sperm from all previous mates are displaced equally, the model of two-male sperm displacement followed by random mixing outlined by Parker et al. (1990) was extended. After a third mating, the last mate will gain a certain proportion of fertilizations, denoted $P_{3}$. If sperm from the first and second males are mixed in storage, then displacement during a third mating is predicted to result in identical declines in paternity success for first and second males. If $P_{\mathrm{i} \mid 3 \mathrm{x}}$ and $P_{\mathrm{i} \mid 2 \mathrm{x}}$ represent the proportion of progeny sired by the $i^{\text {th }}$ male after three or two matings, respectively, then when paternity decline is distributed equally, it is expected that:

$$
P_{2 \mid 3 x}=\left(1-P_{3}\right) \cdot P_{2 \mid 2 x}
$$

and

$$
P_{1 \mid 3 x}=\left(1-P_{3}\right) \cdot P_{1 \mid 2 x}
$$

Therefore, to compare relative declines in paternity success of first vs. second males after a third mating, the null hypothesis tested was:

$$
\frac{P_{2 \mid 3 x}}{P_{2 \mid 2 x}} \geq \frac{P_{1 \mid 3 x}}{P_{1 \mid 2 x}}
$$

\section{Paternity success in double- and triple-matings}

To unambiguously track paternity success for each T. castaneum male, three unique genetic markers were used. All females were wild-type derived from the Berkeley synthetic strain, and males were from three strains; either wild-type, Rap or $R d^{\text {hd }}$. Rap (recurved anterior pronotum) is a spontaneous dominant, homozygous viable mutation affecting the shape of the pronotum. $R d^{\text {hd }}$ (reindeer honey dipper) is another dominant, homozygous viable mutation resulting in swollen antennae; the original Reindeer mutation was described by Dawson (1984). In the present study, males were mated in a fixed order, consisting of wild-type first males, Rap second males, and $R d^{\text {hd }}$ third males, to allow comparisons of first and second male paternity success in double- vs. triple-matings without confounding possible genotype differences in sperm precedence.

Wild-type females were selected as pupae and randomly assigned to mate sequentially with either two or three males. Except when mating, males and females were kept individually in $20 \mathrm{~mL}$ vials with $3 \mathrm{~g}$ of unbleached wheat flour and maintained in a dark incubator at $29^{\circ} \mathrm{C}$ and $70 \% \mathrm{RH}$. In the double-mating treatment, first copulations between virgin females $(n=15)$ and wild-type males were observed, and then females were allowed to oviposit for $24 \mathrm{~h}$ to confirm successful insemination by the first male (based on presence of larval progeny later emerging from fertilized eggs). After $24 \mathrm{~h}$, females were allowed to copulate with a second, Rap male, after which eggs were collected from each female for 10 oviposition periods of 2 days each. Procedures for these first two matings were identical for the 15 females randomly assigned to the triple-mating treatment, except that, $24 \mathrm{~h}$ after their second mating, these females were allowed to mate with a third, $R d^{\text {hd }}$ male. After the third mating, eggs were collected from each female for 10 consecutive 2-day oviposition periods. Progeny were reared for 45 days to allow for completion of adult development, and progeny phenotypes were scored to assign paternity to first, second or third males. Results are expressed as the proportion of each female's progeny that were sired by each mating male $\left(P_{1}, P_{2}\right.$ or $\left.P_{3}\right)$. Only females with confirmed successful inseminations by all (two or three, depending on the treatment) of their assigned mates were included in the analysis: this resulted in final sample sizes of 12 doublemated females and nine triple-mated females. This procedure allowed us to avoid a common problem in which differences among males in their insemination success may be confounded with differential paternity success. 


\section{Data analysis}

Because differences in offspring survivorship among sire genotypes could potentially bias estimates of sperm precedence, egg to adult survivorship was measured separately for crosses between $+/+$ females and males from each of the three strains: $+/+, R a p$ and $R d^{\text {hd }}$ (10 replicates per strain). Mean survivorship was $79.2 \%$ for $+/ R d^{h d}$ progeny, whereas the other two crosses had nearly identical survivorship averaging $65.0 \%$. Thus, triple-matings were corrected for the observed higher survivorship of $+/ R d^{\text {hd }}$ heterozygote offspring by multiplying third male progeny numbers by 0.82 . This correction factor adjusts only $P_{3}$ estimates and did not alter the ratios of paternity success for first and second males, which were the primary focus of this study.

To compare declines in paternity success of first vs. second males after a third mating, statistical analysis software R (version 1.8.1) was used to conduct a nonparametric bootstrap analysis (Efron \& Tibshirani, 1993). In this analysis, data were resampled 2000 times with replacement to construct an empirical resampling distribution and determine bias-corrected adjusted confidence intervals for the parameter $\frac{P_{1 \mid 3 x}}{P_{1 \mid 2 x}}-\frac{P_{2 \mid 3 x}}{P_{2 \mid 2 x}}$. Bootstrap analysis was separately conducted for data from each of the 10 consecutive 2-day oviposition periods, as well as combined data from the entire 20-day period, to determine whether second males showed a greater decline in paternity success compared with first males. Bootstrap $P$-values based on these resampling distributions are reported, and reflect tests of the null hypothesis that $\frac{P_{2 \mid 3 x}}{P_{2 \mid 2 x}} \geq \frac{P_{1 \mid 3 x}}{P_{1 \mid 2 x}}$.

\section{Results and discussion}

After triple-matings, third males gained the majority of fertilizations as expected, and both previous mates showed a corresponding decrease in paternity success (Fig. 1). However, first males retained higher paternity success in triple- compared with double-matings $\left(\frac{P_{1 \mid 3 x}}{P_{2,2 x}}\right)$ than did second males $\left(\frac{P_{2 \mid 3 x}}{P_{22 x}}\right.$; Fig. 2). Bootstrap analysis indicated a significant difference between observed paternity success ratios of male 1 vs. male 2 based on progeny combined over the entire 20 -day oviposition period $(P=0.006)$. This indicates that when females remate, differential sperm displacement results in a long-term reduction in the second male's paternity success. Additionally, the discrepancy between first and second males appeared to be particularly high within the first few days after the last mating (Fig. 2). Bootstrap analysis conducted at individual timepoints indicated that male 1 retained a higher proportion of fertilizations $\left(\frac{P_{1 \mid 3 x}}{P_{1 \mid 2 x}}\right)$ than male $2\left(\frac{P_{2 \mid 3 x}}{P_{2 \mid 2 x}}\right)$ at oviposition day 1 $(P=0.013)$, day $3(P=0.077)$ and at day $5(P=0.025)$, whereas all remaining timepoints showed similar ratios of paternity success for both previous mates (all $0.145<P<0.645)$. These results are consistent with a model of initial stratification of previously stored sperm, in which last-male sperm is located proximally in the female

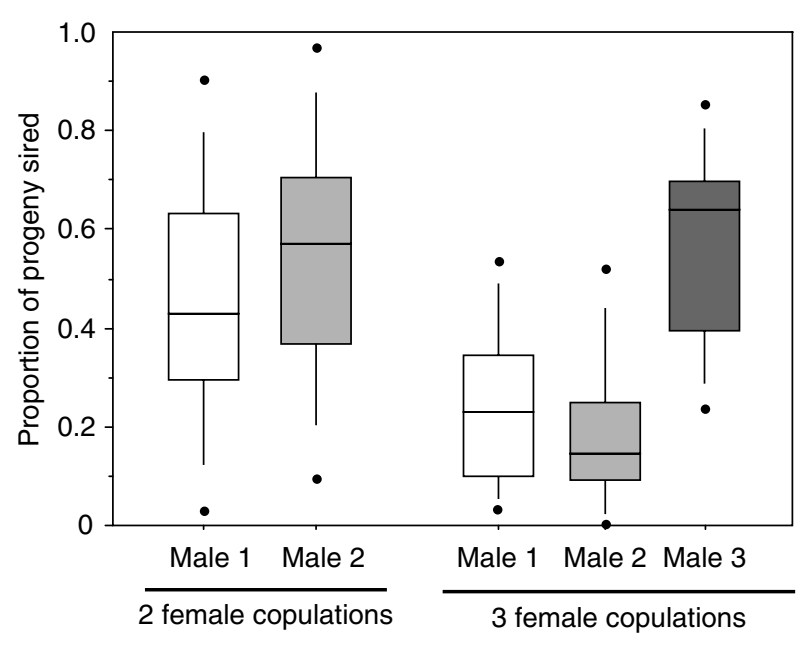

Fig. 1. Proportion of progeny sired by each Tribolium castaneum male after double- and triple-matings by females. Box plots indicate the median and interquartile range (inner box) and the data range. Proportions are based on total number of progeny produced within 20 days after the last copulation by $n=12$ doublemated and $n=9$ triple-mated females.

storage organ, where it becomes more susceptible to displacement when the female subsequently remates.

Detailed knowledge of sperm transfer and storage processes is required to fully understand the mechanisms generating sperm precedence patterns (Eberhard, 1996; Simmons, 2001). Previous work in T. castaneum has demonstrated that only approximately $4 \%$ of sperm transferred to females during a single copulation is moved into long-term storage within the tubular spermatheca, and that such storage is mostly complete within approximately $1 \mathrm{~h}$ (Bloch Qazi et al., 1996). Previous work also indicates that

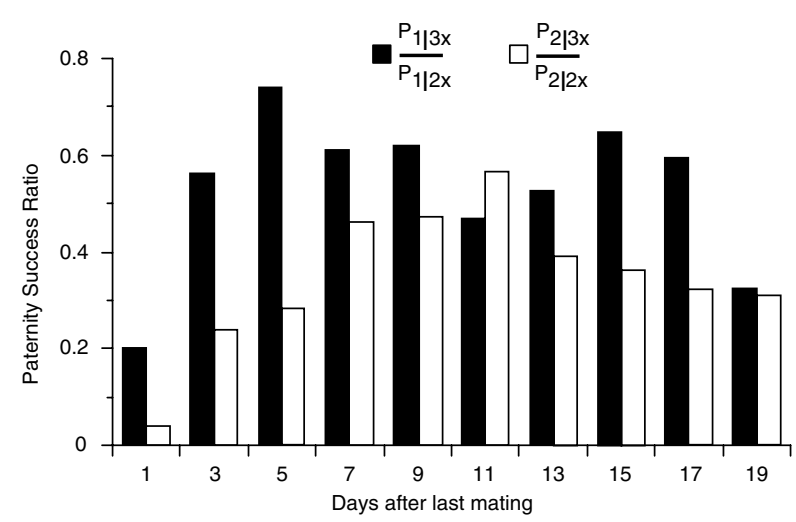

Fig. 2. Temporal changes in paternity success ratios for first and second Tribolium castaneum males. For each 48-h oviposition period (midpoints indicated), bars represent the ratio of paternity success for first and second males after triple-mating (mean proportion of progeny sired, based on $n=9$ triple-matings) compared with paternity success after double-matings (mean based on $n=12$ double-matings). Ratios closer to 1 indicate that males retain greater paternity success when the female remates. 
the female spermatheca is generally filled to capacity after two copulations, and predicts that if stored sperm are spatially stratified, then sperm displacement during subsequent matings will lead to loss of sperm belonging mainly to the second male (Lewis \& Jutkiewicz, 1998). The present study provides evidence for this predicted preferential loss of second male paternity when females remate with a third male within 2 days. These results provide insight into the processes determining male paternity success within the context of natural mating systems. In $T$. castaneum, first males gain a positional sperm defensive advantage because their sperm is stored distally within spermathecal tubules, and is thus protected from subsequent displacement or expulsion. Once the female spermatheca is full, last-mating males gain a sperm offensive advantage and sperm deposited by males mating in middle positions is differentially lost. Thus, different sperm competitive advantages appear to generate high long-term paternity success for those males mating both first and last in the mating order.

In $T$. castaneum temporal changes in last-male sperm precedence indicate that sperm stratification persists for some days after mating, followed by increased mixing of stored sperm (Schlager, 1960; Lewis \& Jutkiewicz, 1998; Arnaud etal., 2001). For example, Lewis \& Jutkiewicz (1998) found high $P_{2}$ for progeny produced within the first $48 \mathrm{~h}$ after females' second matings but, by 1 week, $P_{2}$ did not differ from that expected under a model of random mixing of stored sperm from both males. Thus, a transition from sperm stratification to sperm mixing appears to take place at approximately 2 days postmating. This implies that the differential loss of paternity observed here for a female's most recent mate is likely to occur whenever females remate within 2 days. However, if female remating takes place after sperm stores are mixed, paternity of all previous mates should be equally discounted.

Across species, sperm precedence dynamics are likely to be influenced by many factors, including relative volumes of male ejaculates and spermathecae, whether the female spermatheca is fixed capacity vs. expandable, and spermathecal number and shape (Walker, 1980; Hellriegel \& Ward, 1998; Simmons, 2001). Within tenebrionid beetles, temporal patterns of second-male sperm precedence have been well documented for T. castaneum (Schlager, 1960; Lewis \& Jutkiewicz, 1998; Arnaud etal., 2001; Fedina \& Lewis, 2004), for Tribolium confusum (Vardell \& Brower, 1978), and for Tenebrio molitor (Siva-Jothy et al., 1996; Drnevich, 2003). Interspecific comparisons support the early suggestion of Walker (1980) that spermathecal shape may play an important role in determining the extent of sperm mixing. Tribolium castaneum and T. molitor both have sperm storage organs consisting of multiple elongated, narrow tubules. Under a wide range of mating conditions, both of these species also show a temporal pattern of sperm precedence in which last-male paternity is high immediately after mating, and then gradually declines over time (Schlager, 1960; Siva-Jothy etal., 1996; Lewis \& Jutkiewicz, 1998; Arnaud et al., 2001; Fedina \& Lewis, 2004). By contrast, in $T$. confusum, the spermatheca consists of a wide, chiti- nized, U-shaped chamber (Surtees, 1961). This species lacks a temporal decline in $P_{2}$ (Vardell \& Brower, 1978), consistent with the prediction of greater sperm mixing within the relatively open spermathecal compartment.

In those insects where polyandrous females continuously mature eggs and oviposit throughout their reproductive lifetimes, females may have multiple opportunities to influence their mates' paternity success. Previous work in $T$. castaneum has demonstrated that females play an active role in moving sperm into storage (Bloch Qazi et al., 1998), and also that such differential storage can influence male paternity success (Fedina \& Lewis, 2004). The present study suggests an additional mechanism through which females might influence offspring paternity. $T$. castaneum females could limit paternity of less preferred males by remating with more highly preferred males before sperm mixing occurs. Whether females can manipulate male paternity success depending on mate quality remains to be determined.

\section{Acknowledgements}

Many thanks to Sue Haas for technical assistance, Durwood Marshall for statistical expertise, and to Margaret Allen, Margaret Bloch Qazi, Jonathan Ryder and three anonymous reviewers for their comments on the manuscript.

\section{References}

Arnaud, L., Gage, M.J.G. \& Haubruge, E. (2001) The dynamics of second and third-male fertilization precedence in Tribolium castaneum. Entomologia Experimentalis et Applicata, 99, 55-64.

Bloch Qazi, M.C., Herbeck, J.T. \& Lewis, S.M. (1996) Mechanisms of sperm transfer and storage in the red flour beetle. Annals of the Entomological Society of America, 89, 892-897.

Bloch Qazi, M.C., Aprille, J.R. \& Lewis, S.M. (1998) Female role in sperm storage in the red flour beetle, Tribolium castaneum. Comparative Biochemistry and Physiology A, 120, 641-647.

Dawson, P.S. (1984) The Reindeer mutation and a revision of linkage groups $\mathrm{V}$ and $\mathrm{X}$ in the flour beetle, Tribolium castaneum. Canadian Journal of Genetics and Cytology, 26, 762-764.

Drnevich, J.M. (2003) Number of mating males and mating interval affect last-male sperm precedence in Tenebrio molitor $\mathrm{L}$. Animal Behaviour, 66, 349-357.

Eberhard, W.G. (1996) Female Control: Sexual Selection by Cryptic Female Choice Princeton University Press, Princeton, New Jersey.

Efron, B. \& Tibshirani, R.J. (1993) An Introduction to the Bootstrap. Chapman \& Hall, San Francisco, California.

Fedina, T.Y. \& Lewis, S.M. (2004) Female influence over offspring paternity in the red flour beetle Tribolium castaneum. Proceedings of the Royal Society of London Series B, 271, 1393-1399.

Hellriegel, B. \& Ward, P. (1998) Complex female reproductive tract morphology: its possible use in postcopulatory female choice. Journal of Theoretical Biology, 190, 179-186. 
Lewis, S.M. (2004) Multiple mating and repeated copulations: effects on male reproductive success in red flour beetles. Animal Behaviour, 67, 799-804.

Lewis, S.M. \& Austad, S.N. (1990) Sources of intraspecific variation in sperm precedence in red flour beetles. American Naturalist, 135, 351-359.

Lewis, S.M. \& Iannini, J. (1995) Fitness consequences of differences in male mating behaviour in relation to female reproductive status. Animal Behaviour, 50, 1157-1160.

Lewis, S.M. \& Jutkiewicz, E. (1998) Sperm precedence and sperm storage in multiply mated red flour beetles. Behavioral Ecology and Sociobiology, 43, 365-369.

Parker, G.A. (1970) Sperm competition and its evolutionary consequences in insects. Biological Reviews of the Cambridge Philosophical Society, 45, 525-567.

Parker, G.A., Simmons, L.W. \& Kirk, H. (1990) Analysing sperm competition data: simple models for predicting mechanisms. Behavioral Ecology and Sociobiology, 27, 55-65.

Schlager, G. (1960) Sperm precedence in the fertilization of eggs in Tribolium castaneum. Annals of the Entomological Society of America, 53, 557-560.

Simmons, L.W. (2001) Sperm Competition and its Evolutionary Consequences in the Insects. Princeton University Press, Princeton, New Jersey.

Simmons, L.W. \& Siva-Jothy, M.T. (1998) Sperm competition in insects: mechanisms and the potential for selection. Sperm
Competition and Sexual Selection (ed. by T. Birkhead and A. P. Møller), pp. 341-343. Academic Press, New York.

Sinha, R.N. (1953) The spermatheca in the flour beetle (Tribolium castaneum Herbst). Journal of the New York Entomological Society, 41, 131-134.

Siva-Jothy, M.T., Blake, D.E., Thompson, J. \& Ryder, J.J. (1996) Short- and long-term sperm precedence in the beetle Tenebrio molitor: a test of the 'adaptive sperm removal' hypothesis. Physiological Entomology, 21, 313-316.

Sokoloff, A. (1974) The Biology of Tribolium, Vol. II. Oxford University Press, U.K.

Surtees, G. (1961) Spermathecal structure in some coleoptera associated with stored products. Proceedings of the Royal Entomological Society of London Series A, 36, 144-152.

Vardell, H.H. \& Brower, J.H. (1978) Sperm precedence in Tribolium confusum (Coleoptera, Tenebrionidae). Journal of the Kansas Entomological Society, 51, 187-190.

Walker, W.F. (1980) Sperm utilization strategies in nonsocial insects. American Naturalist, 115, 780-799.

Accepted 20 December 2004

First published online 16 May 2005 